\title{
Monitoring land use and land cover changes in Turkmenistan using remote sensing
}

\author{
L. Orlovsky ${ }^{1}$, S. Kaplan ${ }^{1}$, N. Orlovsky ${ }^{2}$, D. Blumberg ${ }^{3}$ \\ \& E. Mamedov ${ }^{4}$ \\ ${ }^{I}$ Department of Solar Energy and Environmental Physics, \\ Jacob Blaustein Institutes for Desert Research, \\ Ben-Gurion University of the Negev, Sede-Boqer, Israel \\ ${ }^{2}$ Department of Drylands Biotechnologies, \\ Jacob Blaustein Institutes for Desert Research, \\ Ben-Gurion University of the Negev, Sede-Boqer, Israel \\ ${ }^{3}$ Department of Geography and Environmental Development, \\ Ben-Gurion University of the Negev, Beer-Sheva, Israel \\ ${ }^{4}$ National Institute of the Deserts, Flora and Fauna, \\ Ministry of Nature Protection, Ashgabat, Turkmenistan
}

\begin{abstract}
In Turkmenistan the most prominent cause for desertification is inappropriate land use practices. The natural arid pastures have limited carrying capacity and any changes of the fragile balance can lead to the destruction of this valuable resource. One of the most appropriate tools for monitoring these processes is change detection through remote sensing imagery. Accurate monitoring of changes on the Earth's surface is important to understand the relationship between man and nature and to provide decision makers with relevant information. The information on vegetation change is the most important of these relationships. Vegetation cover is also a useful indicator of the magnitude of land degradation that is easily assessed by multispectral remote sensing. The reduced vegetation cover causes an increase in albedo, which can also be monitored by remote sensing. The combination of these two parameters can give us a better map of the pasture status and its degradation rate. Landsat TM and ETM+ images were processed to maps of land use/land cover changes in northern Turkmenistan. The data were further processed in GIS and revealed the shrinking and the degradation of the pasture area. From the 1970s a total of $\sim 4000 \mathrm{~km}^{2}$ of pasture were transformed into agricultural land, increasing the grazing pressure in the remaining areas. By applying advanced techniques for image based end-member retrieval and spectral mixture analysis a sub-pixel fraction was obtained for each end-member. The fractions of soil and vegetation emphasize the most degraded/rehabilitated sectors of the study area. Our results indicate the reduction of vegetation in specific areas while most of the desert experiences an increase in the vegetation cover. Our current study focuses on combining the spectral mixture analysis products with other degradation criteria such as change detection using albedo and vegetation indices to produce a more detailed assessment and understanding of the processes leading to these changes. Keywords: Central Asia, pastures, irrigation, secondary salinization.
\end{abstract}




\section{Introduction}

The Asian continent suffers heavily from desertification, in particular severe salinization, waterlogging, vegetation degradation, and soil erosion. Irrigated agriculture and livestock farming are main branches of Turkmen economy. 95\% (38.34 million hectares) of the agricultural lands of Turkmenistan are used as around-the-year natural desert pastures. During the last 30 years the total livestock number increased from 4,709 thousand (1970) to 7,792 thousand (1996) and 17 million heads (2005), at the same time population increased more than 2.5 times. Consequently, the anthropogenic pressure on these areas has increased. During the Soviet regime organized delivery of water to the distant pastures existed. Nowadays, due to the financial constraints this approach is not feasible. As a result more than $25 \%$ of pastures have not being used because of water lack [1]. The traditional seasonal migrations are ceased. The herds are concentrated around the settlements and near existing watering points all year round ( $\mathrm{ibid}$ ). According to different estimations, from 60 to $80 \%$ of the pastures are degraded at different rates, but the last systematic survey and assessment of desert and marginal lands was carried out in 1980s, while the most dramatic changes occurred during last 10-15 years. The increase in the cultivated irrigation led to 1) increased demand in irrigation water and water for drainage; 2) further rise of ground water level; 3) secondary soil salinization processes.

Since the natural arid pastures have limited carrying capacity, any factor that changes the fragile balance can lead to the destruction of this valuable resource. Changes in vegetation cover and its productivity in the temporal and spatial aspect is probably the most sensitive sign and early indicator to desertification processes; however, it is not an easy task to monitor vegetation state over large areas.

The vastness of Central Asian natural pastures, financial constraints of these newly independent states and lack of the modern technical means restrict proper monitoring of pasture land. Modern and updated assessment of rangelands is essential since dramatic political and economical changes took place all over central Asia.

Remote sensing has been considered to be an appropriate tool for studying changes in the arid and semi-arid environments due to its multitemporal coverage, synoptic view and digital format which enable monitoring of the Earth surface quickly and repetitively for large areas that are difficult to study by conventional methods [2-4]. However, only few studies have been done in Turkmenistan using remote sensing methods.

Usually the Instantaneous Field Of View (IFOV) of a sensor contains more than one land cover type, especially in arid environment that are commonly a combination of vegetation and soil in different proportions, creating mixed pixels. In order to solve the mixed pixels problem the Spectral Mixture Analysis method has been developed. Most studies involved in un-mixing of land cover elements in arid regions used multispectral unmixing techniques, where vegetation fraction was quantified relative to the soil and rock fractions [5-8].

The aim of this study is to assess land use/land cover changes in north Turkmenistan and reveal trends in these changes using remote sensing methods. 


\section{Study area}

The research was conducted in the Dashoguz velayat (province) in northern Turkmenistan located between $39.5^{\circ}-42.7^{\circ} \mathrm{N}$ and $56.4^{\circ}-61^{\circ} \mathrm{E}$. The area of the province is $74,588 \mathrm{~km}^{2}$, it is populated by $1,196.7$ thousands people. The portion of rural population is $68 \%$. Climate is arid with annual average precipitation less than $110 \mathrm{~mm}$ and with notable contrast between seasons and years. Most of precipitation occurs in winter and early spring. Average annual temperatures are $12^{\circ} \mathrm{C}-16^{\circ} \mathrm{C}$ with high seasonal amplitude up to $34^{\circ} \mathrm{C}$ [9]. The province has two main physics-geographic regions: a) the northern flat lowland consisting of Sarykamish depression and adjacent ancient alluvial deltaic plain of Amudarya River with spots of takyrs and small sandy massifs; b) Trans-Unguz Karakum Desert with sub-meridianal vegetated sand dunes and "kyrs"- flat-topped ancient ridges consisting of gypsum and carbonates. The irrigated lands of Dashoguz province constitute more than one quarter of the arable lands in Turkmenistan. One third of Turkmen cotton, more than $80 \%$ of rice and $50 \%$ of corn are cultivated here. Within the study area this paper will focus on the transition zone between irrigated agricultural land of Sarykamish ancient delta and pastures of Transunguz Karakum Desert. This transition zone is strongly influenced by human impact and thus highly dynamic.

\section{Methodology}

\subsection{Selection of images and pre-processing}

The series of Landsat TM (1988) and ETM+ (2004) images have been selected for comparison, providing a full coverage of the Dashoguz province. This choice was determined according to the similarity of precipitation amount and distribution in the rainy seasons of 1987-1988 and 2003-2004. The images were taken in/or close to the presumed peak of vegetation season - at the end of March - beginning of April, when both annual and perennial vegetation is present. Prior to performing multi-temporal image data analysis, geometric, atmospheric and radiometric corrections were carried out in order to improve the image quality and accuracy of analysis.

\subsection{Spectral Mixture Analysis}

The SMA is designed to derive the proportions of different basic land cover components that compose a mixed pixel [4]. We chose the linear model, which assumes that the reflectance of a pixel is a mixture of the reflectance of 'pure' components (end-members) in proportion to the area that they cover:

$$
\rho_{i, j, k}=\sum_{m=1, \rho} F_{i, j, m} \rho_{m, k}+e_{i, j, k}
$$

where $\rho_{i, j, k}$ is the reflectance of the $i, j$ pixel in band $k ; F_{i, j, m}$ is the fraction of the $m$ component in that pixel for each of the $\rho$ pure categories; $\rho_{m, k}$ is the reflectance 
of the pure cover $m$ in the same band $k$, and $e_{i, j, k}$ is the error term for that pixel. The fraction of each pure category covering the pixels of the image $\left(\mathrm{F}_{i, j, m}\right)$ is an unknown value, which is being solved by spectral unmixing of the image. The best mathematical approach is to minimize $e$, using a least-squares solution [10]. The SMA can only be solved if there are less end-members than spectral bands.

According to our results, the SMA provides better estimation of the change processes in the desert comparing to vegetation indices, since both quality and quantity assessment of vegetation and soil proportions are obtained.

The un-mixing procedure was carried out using ENVI 4.1 software. The main end-members of the area are sandy soil and vegetation represented by Haloxylon $s p$., Salsola sp. and Callygonum bushes. In the transition zone between the desert and irrigated area, water starts playing a significant role and is included as an end-member for that part of the image solely.

The increase in vegetation fraction in the desert area points on rehabilitation processes, and vice versa. The presence of water in the desert transition area indicates the process of flooding due to the leakage from the canals and flow of drainage water from the irrigated fields.

The vegetation and sand signatures were measured in five wavelengths corresponding to the Landsat bands in the field using CropScan portable radiometer. The water spectral signature was taken from [11], who measured it at six wavelengths, fig. 1 .

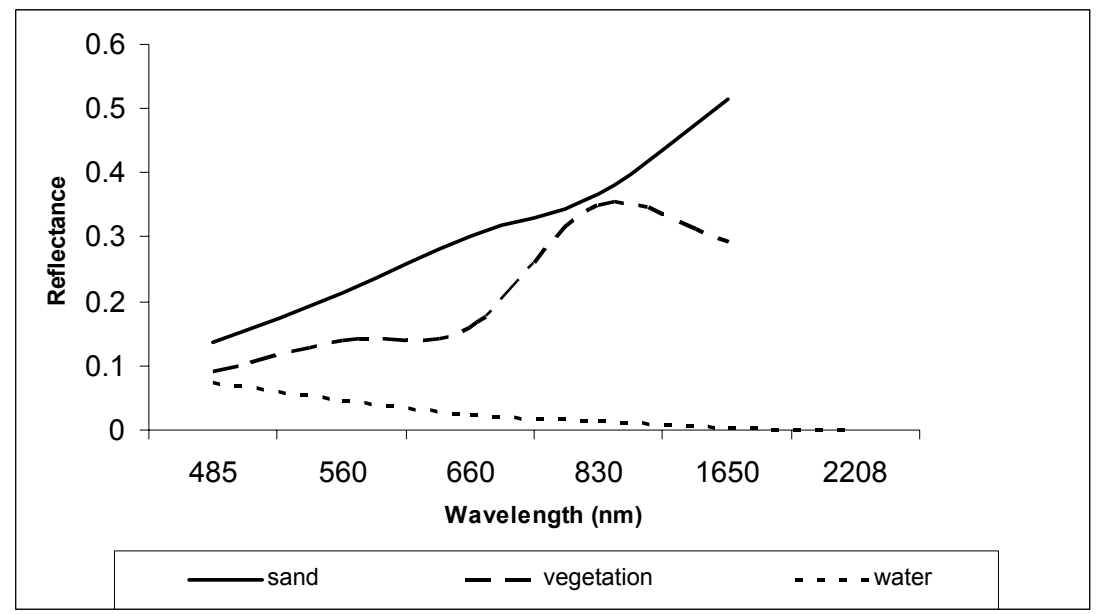

Figure 1: Spectral signatures used for unmixing algorithm.

\subsection{Image differencing}

Change detection is the process of identifying differences in the state of an object or phenomenon by observing it at different times. Using GIS and image differencing technique NDVI, SAVI and soil and vegetation fraction were calculated. The resulting image indicating the changes occurred in 1988-2004 was produced by subtracting the previous image from the subsequent one. 


\section{Results}

\subsection{Land use changes}

There are two main types of land use in the study area - irrigated agriculture and natural pastures' use. The irrigated area was calculated from the time series of the Landsat images using GIS 9.0 software, fig. 2. The cultivated area in this region of Turkmenistan almost doubled in the last three decades, while the most rapid increase took place between 1973 and 1987, coinciding with development of large-scale irrigation in Central Asia for growing cotton. After collapse of the USSR in early 1990's the irrigated area keeps growing - again on the account of adjacent pastures - at that time mainly for growing wheat.

\subsection{Vegetation cover changes}

Change detection analysis of the Normalize Difference Vegetation Index (NDVI) and Soil Adjusted Vegetation Index (SAVI) images showed that areas around watering points and wells and other man made features such as gas pipes experienced degradation while in most pasture areas positive changes took place in 1988 - 2004. Anyhow, such analysis gives only qualitative assessment and shows the trend of changes. In attempt to quantify these changes we applied the SMA, assuming that a pixel of image taken from Trans-Unguz Karakum consists of two end-members - sand and vegetation. In the pixels/areas, which undergoing the negative changes (decrease in NDVI and SAVI values) the unmixed vegetation fraction doesn't exceed $25-30 \%$. It occurs in the areas around watering point, at the tops of sandy ridges, and in the areas of so-called technogenic desertification (near newly constructed canals, water- and gaspipes). Unmixed values of vegetation fraction in the inter-ridge depressions and lower parts of the ridges' slopes, which were identified by vegetation indices as positively changed, ranges from 45 to $60 \%$.

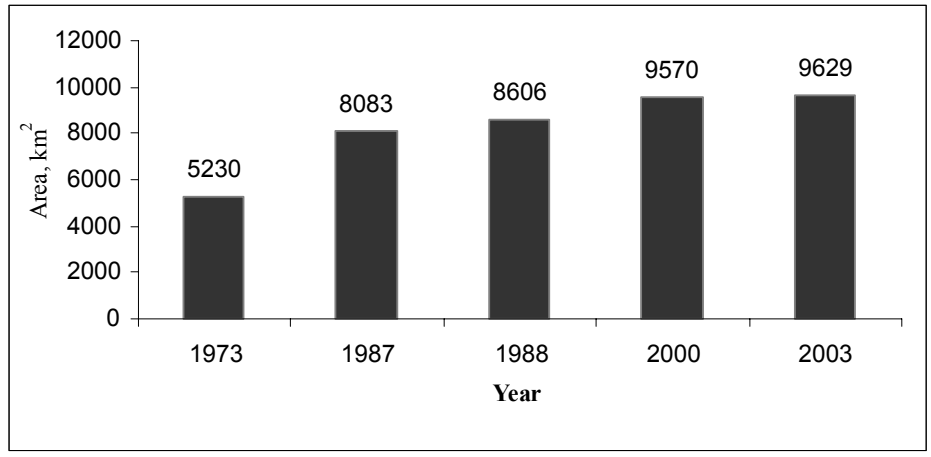

Figure 2: Increase of cultivated area in Dashoguz province of Turkmenistan.

Figure 3 shows the results of the change detection procedure for the vegetation fraction. The trends of the changes revealed by vegetation indices are 
confirmed by SMA change detection. Most of the area experiences an increase in vegetation cover by $10 \%-15 \%$, except desertification plots around the water points and wells, water- and gas-pipes. Usually the radius of desertification plots around the well in the Karakum Desert is 5 or even $10 \mathrm{~km} \mathrm{[12]} \mathrm{-} \mathrm{according} \mathrm{to}$ daily migration route of sheep. However, the current situation differs from the traditional concept: both images and field survey carried out in spring 2006 reveal the rehabilitation processes at the distance of $800 \mathrm{~m}$ and even less from the well. Moreover, further advance from the "epicenter" of desertification plot around Ajikui well $\left(41.079^{\circ} \mathrm{N}, 59.386^{\circ} \mathrm{E}\right)$ revealed developing biogenic crusts ("karakharsangs) consisting of moss Tortula desertorum, lichens and cyanobactreia, which serves as indicator of undergrazing -degradation of vegetation due to under-use [13]. The situation is similar near the water- and gas-pipes, although without biogenic crusts.

Our initial assumption/hypothesis was that the remote desert pastures are rehabilitating, while vegetation in the areas adjacent to oases is degrading. Image analysis showed the opposite: areas adjoining irrigated massif are undergoing the rehabilitation. Field survey revealed that in these areas, which were classified as degraded in late 1980s, Haloxylon aphyllum (traditional firewood for the local dwellers) was planted as part of combating desertification measures. Since the gas-pipe has been constructed approximately at the same time and free natural gas is supplied to local population, cutting of trees and shrubs for firewood ceased.

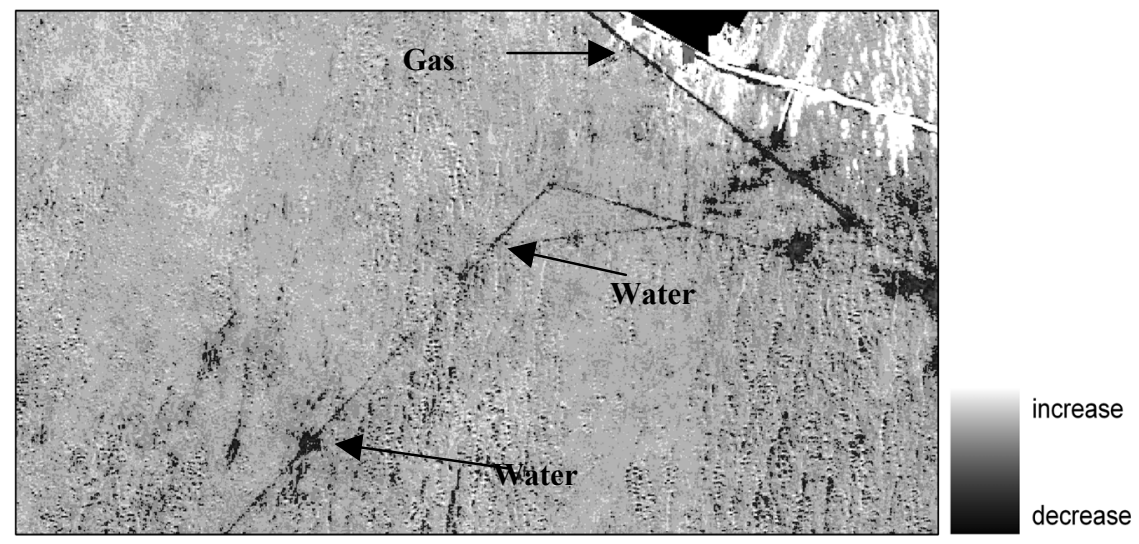

Figure 3: Change of vegetation fraction image. Brighter colors represent rehabilitation of vegetation and darker colors represent degradation.

\subsection{Water logging and flooding}

The processes of water logging and flooding take place mainly in the boundary area between irrigated fields and desert. They occur as a result of 1) filtration of water from the irrigation canals, which were constructed without waterproof isolation, and 2) discharge of excessive irrigation water and drainage water to the 
adjacent desert areas. In spite of increase of vegetation cover and productivity around filtration lakes and waterlogged areas, this process is considered as pasture's degradation, since the available pasture is shrinking, hydrophilic species in many cases are unpalatable, and the migration routes of the livestock is disturbed. The SMA shows the increase of flooded area in Trans-Unguz Karakum from $93 \mathrm{~km}^{2}$ in 1988 to $268 \mathrm{~km}^{2}$ in 2004 (including irrigation and drainage canals), fig. 4.
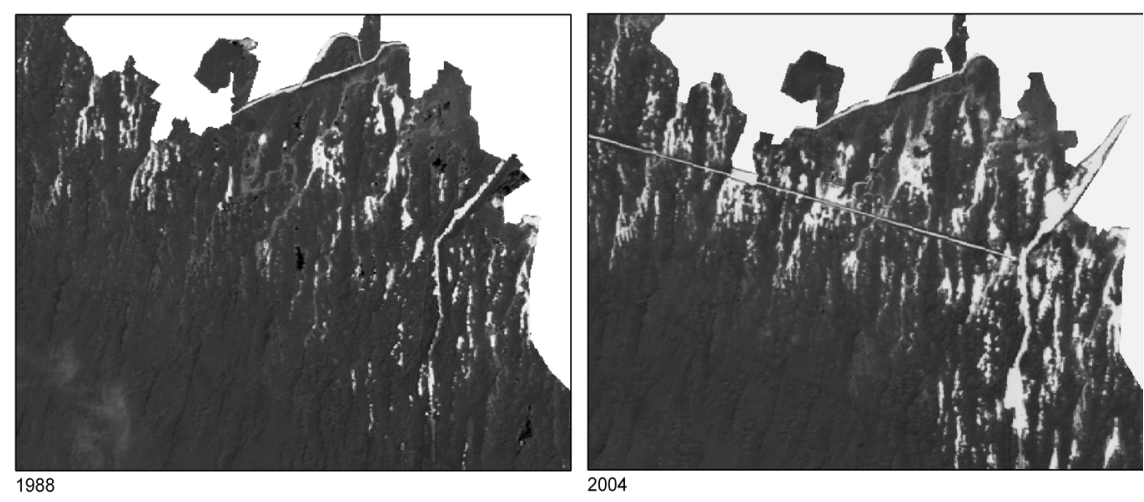

Figure 4: Water component comparison. Brighter colour represents higher water fraction.

\subsection{Secondary soil salinization}

While the most natural pastures of the Dashoguz province are undergone the rehabilitation processes, the situation in the irrigated areas is just opposite: there are no irrigated fields, which are not salinized. The main reasons of secondary salinization of irrigated lands in Dashoguz are: 1) improper quality of irrigation water; 2) antiquated irrigation techniques; 3) excessive irrigation rates; 4) improper soil washing. Salinity of Amudarya River water (the main source of irrigation water) increased from 0.2-0.4 g per litre at the beginning of $1960 \mathrm{~s}$ to 2-2.5 g/l at present due to return flow of highly salinized drainage water to the River. Every year from 9 to 32 tons of salts per hectare are brought to the cotton field [14]. Irrigation canals (both main and intra-farming) have been constructed directly in the ground without impervious cover, which leads to the high losses during transportation (up to $25 \%$ ) and formation of filtration lakes. The large size of the fields and out-of-date irrigation techniques (flooding and furrow irrigation) makes impossible application of biologically required irrigation rates -8.88 thousand $\mathrm{m}^{3}$ per hectare. The length of the drainage network is about $10,000 \mathrm{~km}$, or 22.3 running meter per irrigated hectare, which provide about one third of irrigated lands by drainage. The volume of produced drainage water in the province is $2.72 \mathrm{~km}^{3}$ with average salinity $4.38 \mathrm{~g}$ per litre. The main reason of soil salinization is the high level of ground water. Insufficient effectiveness of the drainage network leads to increase of the ground water level $-94 \%$ of the irrigated lands are in the area with ground water depth less than $3 \mathrm{~m}$. 


\section{Conclusions}

Vegetation is an important natural resource of Turkmenistan's desert. However, since the 1980's no research was carried out concerning the ongoing changes of vegetation cover in the desert pastures. In spite of the sparse desert vegetation and relatively low spatial resolution Landsat imagery gives the correct results on the current changes occurring in the arid lands of Turkmenistan. Primary results of this research show the potential of Spectral Mixture Analysis for accurate vegetation mapping and land change detection. The vegetation change detection procedure shows that although there is a reduction in the available area for pasture in Dashoguz province of Turkmenistan due to expansion of irrigated fields, most of the pasture area is rehabilitating. The water end-member analysis shows the leaks from the irrigation and drainage canals, which are causing flooding and water logging on the account of pasture area, thus, triggering more degradation. Mismanagement of native pasture may harm natural re-vegetation of dunes by palatable species, which are well adapted to the arid environment and uses as livestock food. By using remotely sensed data this valuable resource is better understood and preserved for an ongoing sustainable development. However, further research is necessary, which will include developing of a complete unmixing algorithm.

\section{Acknowledgement}

The authors express their sincere gratitude to U.S. Agency for International Development for funding the project CA22-010, which made this study possible.

\section{References}

[1] Babaev, A. G. (ed.). Desert problems and desertification in Central Asia. Springer: Berlin, pp. 260, 1999

[2] Singh, A., Digital change detection techniques using remotely sensed data. International Journal of Remote Sensing, 10, pp. 989-1003, 1989.

[3] Mas, J. F., Monitoring land cover changes: a comparison of change detection techniques, International Journal of Remote Sensing 20, pp. 139-152, 1999.

[4] Collado, A. D., Chuvieco, E., Camarasa, A., Satellite remote sensing analysis to monitor desertification processes in the crop-rangeland boundary of Argentina, Journal of Arid Environment 52, pp. 121, 2002.

[5] Pech R. P., Graetz, R. D., Davis, A.W., Reflectance modelling and derivation of vegetation indices for an Australian semi-arid shrubland, International journal of remote sensing 7(3), pp. 389-403, 1986.

[6] Smith, M. O., Ustin, S. L., Adams, J.B., Gillespie, A.R., Vegetation in deserts: I. A regional measure of abundance from multi-spectral images, Remote Sensing of Environment 31, pp.1-51, 1990.

[7] Shoshany, M., Kutiel, P., Lavee, H., Monitoring temporal vegetation cover changes in Mediterranean and arid ecosystem using a remote 
sensing technique: case study of the Judean mountain and the Judean desert, Journal of Arid Environment, 32, pp. 1-13, 1996.

[8] Ustin, S. L., Hart, Q. J., Duan L., Scheer G., Vegetation mapping on hardwood rangeland in California, International Journal of Remote Sensing, 17, pp. 3015-3036, 1996.

[9] Orlovsky, N. S., Climate of Turkmenistan. Biogeography and Ecology of Turkmenistan. V. Fet and K. I. Atamuradov (eds.). Kluwer Academic Publishers: Dordrecht / Boston /London, pp. 23-48, 1994.

[10] Shimabukuro, Y. E., \& Smith, J. A., The least squares mixing models to generate fraction images derived from remote sensing multispectral data, IEEE Transactions on Geoscience and Remote Sensing, 29, pp. 16-20, 1991.

[11] Small C., The Landsat ETM+ spectral mixing space. Remote Sensing of Environment 93, pp. 1-17, 2004.

[12] Babaev, A.G. (ed). Productivity of vegetation in Central Karakum Desert under different regime of use. Nauka: Moscow, pp.255, 1979.

[13] Orlovsky, L., Dourikov, M., \& Babaev, A., Temporal dynamics and productivity of biogenic soil crusts in the Central Karakum desert, Turkmenistan, Journal of Arid Environments 56(4), pp. 579-601, 2004.

[14] Esenov P., Ecological and ameliorative state of irrigation zone of Dashoguz velayat of Turkmenistan, Problems of desert Development, $\mathbf{6}$, pp. 29-34, 1995. 